Faculty of Education

Te Kura Toi Tangata

Waikato Journal of Education

Te Hautaka Mātauranga o Waikato

Volume 16, Issue 2: 2011 


\section{WAIKATO JOURNAL OF EDUCATION TE HAUTAKA MĀTAURANGA O WAIKATO}

\section{Editors:}

Jane Strachan

Noeline Wright

\author{
Editorial Board: \\ Beverley Bell \\ Bronwen Cowie \\ Deborah Fraser \\ Margie Hohepa \\ Sally Peters \\ Noeline Wright
}

\author{
Margaret Carr \\ Rosemary DeLuca \\ Richard Hill \\ Judy Moreland \\ Clive Pope
}

Waikato Journal of Education is a refereed journal, published annually, based in the Faculty of Education, The University of Waikato, Hamilton, New Zealand. It publishes articles in the broad field of education. For further information visit the WJE website http://edlinked.soe.waikato.ac.nz/research/journal/index.php?id=8

Correspondence and articles for review should be addressed to: Research Manager, Wilf Malcolm Institute of Educational Research, Faculty of Education, The University of Waikato, Private Bag 3105, Hamilton, 3240, New Zealand. Email: wmier@waikato.ac.nz

Business correspondence: Orders, subscription payments and other enquiries should be sent to the Administrator, Waikato Journal of Education, Wilf Malcolm Institute of Educational Research, Faculty of Education, The University of Waikato, Private Bag 3105, Hamilton, 3240, New Zealand, Email: wmier@waikato.ac.nz

Subscriptions: Within NZ \$40; Overseas NZ \$50

Copyright: (C) Faculty of Education, The University of Waikato

Publisher: $\quad$ Faculty of Education, The University of Waikato

Cover design: Donn Ratana

Printed by: Waikato Print

\section{Call for papers}

The Waikato Journal of Education provides an avenue of publication for quality articles on education. This peer-reviewed journal welcomes a range of topics including interdisciplinary, philosophical and applied research approaches.

Submissions are now invited for consideration for publication in the November 2012 issue. Please submit an electronic copy and a separate page with author/s contact details by 30 April 2012 to WMIER Research Manager, Carolyn Jones (cjjones@waikato.ac.nz), Faculty of Education, University of Waikato, Private Bag 3105, Hamilton 3240, New Zealand. 


\section{Waikato Journal of Education}

\section{Te Hautaka Mātauranga o Waikato}

Volume 16, Issue 2: 2011

\section{Special Edition: A teacher education partnership between the Solomon Islands and New Zealand}

Editorial

The Solomon Islands School of Education Partnership: Aspirations, context and design in educational change

Clive McGee and Patricia Rodie

Partnership experiences in developing the Preparation for Tertiary Learning course in the Teachers in Training programme

Roselyn Maneipuri, Immaculate Runialo and Noeline Wright

Making sense of health education in the Solomon Islands

Kirsten Petrie and Mark Tehe

The Solomon Islands mathematics: Pedagogy in transition?

Nigel Calder, John Beuka and Calvin Ngatulu

Taking ownership: The story of a successful partnership for change in a Pacific Island science teacher education setting

Richard Edwards, Solomon Pita and James Porakari

Funds of knowledge: Developing a Diploma in Teaching in Early Childhood Education in the Solomon Islands

Janette Kelly, Joanna Daiwo and Viola Malasa

Weaving a "Hybrid Mat": Samoa meets the Solomons

Barbara Whyte

Sustaining organisational change: Teacher education in the Solomon Islands Jane Strachan, Susanne Maezama and Janine Simi

Exploring factors that influence school planning in community high schools in the Solomon Islands: Principals' perspectives

Samuel Aruhu and David Giles

Experiences of being a leader in Choiseul Province: Opening principals' and deputy principals' contexts of leadership

John Sisiolo and David Giles

Book review 
Waikato Journal of Education

Te Hautaka Mātauranga o

Volume 16 Issue 2: 2011

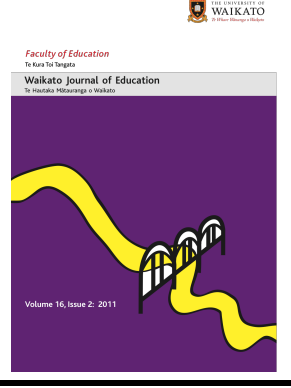

\title{
Experiences of being a leader in Choiseul Province: Opening principals' and deputy principals' contexts of leadership
}

\section{John Sisiolo}

School of Education

Solomon Islands School of Education

\section{David Giles}

School of Education

Flinders University

\begin{abstract}
The prolific growth of community high schools in the Solomon Islands coincides with a shortage of qualified leaders and teachers. Indeed the context for those currently in leadership is complex and greatly influenced by the local community. In this context, being in leadership positions the principal in an intense set of changing interrelationships. Using a case study approach, the context of eleven school leaders in the six community high schools was explored for themes which would open understandings of what it is like to "be" a leader in Choiseul. The findings of this research raise a number of issues for those concerned with educational leadership and the context of leadership in Choiseul. Of concern is the physical and emotional impact of the remoteness and isolation, which is seen as a major impediment to leadership preparation and ongoing professional development. The findings also showed that school leaders were typically influenced by the local community. The research findings provide the basis for a reconsideration of policies and practices that might support and enable current and future school leaders in Choiseul.
\end{abstract}

\section{Keywords}

School leadership, contextual leadership, ontology, Solomon Islands. 


\section{Background}

This article reports on a research project which explored principals' and deputy principals' experiences of "being-in" leadership in community high schools (CHS) in the Choiseul Province of the Solomon Islands (Sisiolo, 2010). Choiseul is a one-island province with nine CHS established by local communities with the assistance of provincial and church educational authorities, and the Ministry of Education. As the name suggests, CHS are controlled by a local community with the support of education authorities and the Ministry of Education.

An increasing population, and the need for access to secondary education in the community, has seen the expansion of CHS. Between 1995 to 1998, 117 CHS were established. The rate of growth and the lack of effective monitoring of the establishment, management and leadership of CHS are major issues. Other issues include the scarcity of curriculum materials, qualified teachers and school leaders. More specifically, the number of qualified teachers and school leaders in the Solomon Islands does not meet the demand from CHS. Further, the majority of CHS were built with support from the local community in terms of the land, materials, labour, and provision of homestay accommodation for students. With this level of support, local communities expect to have a high degree of direct involvement and participation in the schools.

While the Solomon Islands had an estimated population of 508,000 in 2007, the community populations where CHS are established have a population of less than 1000 (Ministry of Environment, Conservation and Meteorology, 2008). These CHS are thus classified as rural and remote with some remote schools being at least a day's travel to the nearest urban centre.

Three major concerns for rural and remote schools are provision, accessibility and quality of education (Connell, 1993; Stern, 1994; Strokes, Stafford, \& Holdsworth, 1999; Suvorova, 2004; Wallin, 2008). In terms of provision, many rural and remote schools are often not provided with the same levels of resources and grants compared to urban schools. Similarly, DeYoung (1991) notes that school leaders in remote schools were normally denied access to professional development by poor management, expensive communication services and transport difficulties. In response to these rural and isolation issues, many experienced leaders tend to look for employment opportunities elsewhere. Stern (1994) found that only young principals and principals who are less educated with lower pay remain in rural and remote schools.

The recent introduction of foreign assistance in the Solomon Islands in the form of manufactured building materials by the Australian Agency for International Development (AusAID), the European Union (EU), and the New Zealand Aid Programme and the World Bank (Sikua, 2002) has provided a new opportunity for rural school development. Assistance from these sectors tends to boost community morale and prioritises the school's physical development.

Current and aspiring leaders in CHS are required to engage with this very complex context. A widening range of official expectations, a shortage of teachers and resources, the observation and availability of leaders personally and professionally, and the governance of a local community that is physically and emotionally close to the school influences a leader's way of "being in" leadership. This article reports on a research 
project that captures a greater sense of the lived realities of school leaders within this context.

\section{Methodology}

The methodology will position the authors, outline the research approach, data gathering and analysis, and comment on questions of reliability and validity in relation to the research.

\section{Positioning the authors}

John is an indigenous citizen of Choiseul. He completed his initial primary teacher education in 1993. Realising the need for effective leadership in schools, John studied educational leadership through distance and flexible learning modes, enabling his promotion to positions of leadership. In the early stages of his leadership experience, local communities were instrumental in John's appointment.

After returning with a higher qualification from the University of the South Pacific in 2004, John was asked to be a head of department in a CHS. His active involvement in the leadership roles in CHS became a springboard to his appointment as a lecturer at the School of Education in the Solomon Islands College of Higher Education. Eight years' experience as a school leader in the Choiseul Province had given John numerous experiences of the context of school leadership.

David is one of John's critical friends who supported John through his research inquiry. David's particular interest in this inquiry was the hermeneutic interpretations of the participants' experiences towards emergent themes (Giles, 2008). In this way, together we sought to complement each other's knowledge of context and method.

\section{Case studies}

A case study research approach was adopted as the study was conducted in Choiseul Province, one of the nine provinces in the Solomon Islands. Choiseul Province has six CHS registered by Choiseul Province Education Authority. The research involved eleven principals and deputy principals in these schools. The research focused on their experiences of being in leadership.

\section{Semi-structured interviews}

Semi-structured interviews enabled the gathering of in-depth experiences from principals and deputy principals. Prepared questions assisted in guiding the interview conversation (Cohen, Manion, \& Morrison, 2007). The participants preferred the interview to be conducted in Pidgin English (the national language), a language John was also fluent in.

\section{Analysis of data}

The data collected from eleven school leaders in the six CHS focused on what is like to "be" an educational leader in the Choiseul Province. The recorded interviews were translated and transcribed. Themes appearing often in the scripts became the focus for written narratives (Giles, 2008; Lind, 2001). 


\section{Ethics}

This research gained ethical approval from the University of Waikato Faculty of Education ethics committee as well as general approval from the Solomon Islands Ministry of Education and Human Resources Development.

\section{Findings and discussion}

Eight themes were identified through the use of a thematic and interpretive analysis of the data (Giles, 2008). These themes are presented with the support of participants' narratives and the literature. Please note that the names are pseudonyms.

\section{Rural, remoteness and isolation}

Many of the principals in this research found the remoteness and isolation were "push factors" that forced school leaders to transfer out of Choiseul. For some principals and deputy principals, the appointment in a remote CHS prevented them from accessing opportunities for formal professional development. For other principals, the lack of incentives for serving in remote CHS was a push factor. Many school leaders contended that they were working in isolation with a lack of leadership assistance from educational authorities. As such, the situation had not encouraged the growth of effective leadership in the province. One principal recalled that the education authority had not visited him for many years. For others, the vulnerability of being involved in community problems was a push factor. The remoteness and isolation also calls for school leaders to wear many "hats". Indeed, rural communities often measure the quality of leadership by the skills and knowledge a school leader has. As one principal commented, local indigenous folk appear to respond differently to the push factors:

Community high schools in Choiseul Province are situated in the remote communities so they do not attract educational leaders. Thus, only the indigenous educational leaders and teachers of the community within the catchment area of the school are willing to be posted and even committed [to] school leadership.

\section{Shortage of leadership}

The participants suggested that Choiseul Province had a shortage of qualified leaders in CHS. At times, the leadership shortage was a result of the instability in the country and included the effects from the Bougainville crisis in Papua New Guinea, which forced leaders to transfer to other provinces. The shortage of leaders was evident in one deputy principal's appointment, where she described her appointment to the role as "a reward and not ... attached to a leadership qualification". Officially, the Solomon Islands Teaching Service Teaching Handbook (Ministry of Education \& Human Resource Development, 2007a) stipulates that the education authority has to advertise vacant posts for principals and deputy principals. This was not the case for the participants in this research. Only one of the school leaders applied for their position. Although a qualification in educational leadership is one of the key selection criteria in appointment to a leadership role, the participants acknowledged that their appointment was based on their years of experience. Similarly, an education officer in Choiseul Province confirmed that the shortage of qualified secondary school teachers had resulted in the 
appointment of some primary school head teachers as school leaders in secondary schools. This research found that four participants with primary teaching qualifications and with an average of five years' experience in leadership roles were appointed as principals and deputy principals in secondary schools.

\section{Lack of leadership preparation and ongoing professional development}

Most of the participants alluded to not being prepared for their leadership position. In addition, ten of the participants did not have any mentoring in their first appointment. More specifically, five participants who had been primary school head teachers were promoted to principal and deputy principals in secondary schools. This accentuated their concerns about not being as prepared for leadership as those with secondary teaching qualifications. The following narrative echoes this:

I was afraid and not confident because I was not prepared for leadership in the secondary school. I am only a primary school teacher ... even prior to my leadership appointment in primary school I was not prepared. I was only given a copy of the teaching service handbook.

With insufficient knowledge of secondary education, many primary school head teachers received negative responses in their initial secondary principal role. In some schools, the rate and progress of the school's development, people's response to leadership, relationships between the leader and teachers, students and the community, and students' attitude towards learning and academic performances were closely related to the principal's lack of leadership preparation.

Participants stated that being in leadership roles was made more difficult by the lack of ongoing professional development. One participant expressed this concern as follows:

For almost twenty years in my principalship, [educational] authorit[ies have] ... not organised workshop[s] for building leadership capacity for the principals; only workshops that focused on curriculum and financial management have been organised by the Ministry of Education.

The participants who were senior principals suggested that any leadership preparation in the future should be a combined initiative between the Ministry of Education and Human Resources Development, the provincial education authorities, and the school leaders themselves. This could work in response to the need for proper co-ordination of flexible learning and the dissemination of information for teachers and leaders in remote locations.

\section{Appointment procedures}

The Choiseul education authority has traditionally opted for direct appointments due to scarcity of potential leaders and experienced teachers, rather than operating an open appointments procedure in line with the stated national regulations. The general feeling among principals and deputy principals was of being appointed but not supported by the authority. It was a concern to many participants that there was no mechanism in place to prepare newly appointed leaders with a basic knowledge regarding their job. One participant noted the absence of official professional learning over a long period of time: 
I only have [a] certificate in teaching primary for almost thirty years as school leader and often worked in isolation to develop my leadership capacity.

Similarly, another participant explained that their leadership experience involved searching "all the shelves to find any documents to guide me where to start in my leadership". Interestingly, none of the principals and deputy principals had pursued further leadership studies after gaining their first qualification.

The small population and tightly knit communities in Choiseul means that sometimes leadership appointments were influenced by individuals in the local communities. One participant had been the principal in a CHS for more than a decade through the influence of the landowners of the school land. Communities have a significant influence on school leadership due to their substantial contribution to the physical development of the community high schools as almost all the schools in Choiseul were established on customary land.

\section{Community influence and involvement}

All the school leaders noted the community's influence in acquiring principalship and deputy principalship positions in CHS. Communities, individual elites (those whom the community thinks are most important), and interest groups (like politicians) make recommendations to the education authorities to formalise leadership appointments. Failure to comply with community recommendations and suggestions could mean that a school can suffer the withdrawal of community support in donating free resources and labour.

\section{Priority of school physical development}

The first community high schools in Choiseul were established about ten years ago. The most recent was begun in 2009. The school's physical development remains a major priority. According to the Solomon Islands National Action Plan 2007-2009 (Ministry of Education and Human Resources Development, 2007b), when secondary sections are added to primary schools, local communities, assisted by churches or provincial authorities, build the classrooms and manage these schools.

Successful implementation of the school's physical development plan was a high priority and has been used by communities as a measuring device of school leaders' effectiveness. Many participants commented that school developments have been slowed and impeded by factors such as land disputes, remoteness, resource disputes, lack of funding, community support and the quality of school leadership and supervision. Some participants experienced strong community support for their school development. Such support influenced one participant's promotion from head teacher of a primary school to principal of a secondary school.

\section{Gender}

Traditionally, men in Choiseul have ownership of the family inheritance and leadership rights over women. As in any patriarchy, men exercise autocratic leadership even over their extended families. These beliefs and rights have some influence over school leadership in the CHS. As many of the CHS are still in the process of being physically developed and situated in village communities, men are traditionally seen as being more 
effective leaders compared with women. In this study, all the school principals were men.

In addition to patrilineal beliefs about leadership, the women's qualifications as primary school teachers made it more difficult for some participants to be accepted by some community members and some male teachers. Often women sought to withdraw from their leadership role when confronted by a male's discontent even though they held a higher position of authority. One participant, an indigenous person with many years in school leadership in Western Province, made the following comments:

One thing I found in Choiseul that eliminated women in school leadership was culture. Choiseul Province is different from Western Province in some ways when it comes to observance of people's culture. Women were not given equal opportunity as men to undertake leadership role[s.] Periodically, the community deliberately coldshouldered my leadership. Often, this attitude discouraged me [so] that I wish[ed] I could go back to teach in the Western Province.

Culture has had a great impact on the choice of principal and deputy principal in the CHS. However, there are always expedient circumstances. The appointment of four female educational leaders occurred during a period of critical shortage of school leaders.

\section{The need for transparency}

Many participants said that there was a need for greater transparency in the appointment of school leaders and in school leaders' professional practices. Communities demand the school leader's transparency on school-funded projects. One participant stated:

The community and many of the staff are often concerned ... [with] how the school money is spent on the school funded projects when the principal is also school accountant and the school accounts have not been audited. Lack of transparency and accountability in the school budget can easily diminish the good reputation of the school leader.

In a similar way, the Ministry of Education and Human Resources Development has reiterated the rights of parents and guardians to know the income and expenses of the school. This announcement has motivated communities to demand transparency from the school and its leaders. A wide range of experiences have been described which give a feel for what it is like "being" in leadership in a CHS in Choiseul.

\section{Conclusion}

This article reports on a research inquiry that sought to capture school leaders' experiences of "being" in leadership in a one-island province in the Solomon Islands. The leaders' context and experiences have been opened for interpretation. The participants in this research were situated in rural and isolated communities in Choiseul, far from the nearest provincial town and essential services. This context appears to limit and impede the professional growth of these school leaders. The critical shortage of school leaders and the absence of professional development are factors behind many long-serving leaders become stagnant and unproductive. Most of the participants felt that school leadership could be improved through effective planning, management, co- 
ordination, and teamwork amongst existing leaders in the province. The lack of ongoing support in professional learning for school leaders is a key leadership issue in the Solomon Islands.

The purpose of this case study was to explore what it is like "being" an educational leader in Choiseul Province in the Solomon Islands. While school leaders are indigenous to the community, the tie with the community can be constraining at times. The relational "fit" with the local community is one that needs to be managed and supported. Without adequate resources, leaders can be under pressure from the local community.

While the participants' experience of "being" in leadership are unique, the emergent themes suggest that these leaders experience many similar challenges in their particular contexts. "Being" in leadership in CHS draws upon leaders' entire lives as they are set within the context of their local community.

\section{References}

Cohen, L., Manion, L., \& Morrison, K. (2007). Research methods in education (6th ed.). London, England: Routledge.

Connell, W. F. (1993). Reshaping Australian education 1960-1985. Hawthorn, VIC, Australia: ACER.

DeYoung, A. (Ed.). (1991). Rural education: Issues and practice. London, England: Gardland Publishing

Giles, D. L. (2008). Exploring the teacher-student relationship in teacher education: A hermeneutic phenomenological inquiry (Unpublished doctoral thesis). Auckland University of Technology, Auckland, New Zealand.

Lind, V. (2001). Designing case studies for use in teacher education. Journal of Music Teacher Education, 10(2), 7-13.

Ministry of Education and Human Resources Development. (2007a). Solomon Islands Teaching service handbook. Honiara, Solomon Islands: Author.

Ministry of Education and Human Resources Development. (2007b). National education action plan 2007-2009. Honiara, Solomon Islands: Author.

Ministry of Environment, Conservation and Meteorology. (2008). Solomon Islands adaption programmes of action, Retrieved September 28, 2009, from http://www.preventionweb.net

Sikua, D. D. (2002). The decentralisation of education in a developing country: A case of community high schools in the Solomon Islands (Unpublished doctoral thesis). University of Waikato, Hamilton, New Zealand.

Sisiolo, J. L. (2010). "Being" an educational leader in Choiseul Province in the Solomon Islands: A case study of the context of leadership for principals and deputy principals (Unpublished master's thesis). University of Waikato, Hamilton, New Zealand.

Stern, J. (Ed.). (1994). The condition of education in rural schools (ERIC Document Reproduction Service No. ED 371 935). Retrieved November 2, 2009, from ProQuest Eric database.

Strokes, H., Stafford, J., \& Holdsworth, R. (1999). Rural and remote school education: A survey for the human rights and equal opportunity commission. Youth Research Centre, 1, 72. Retrieved September 27, 2009, from

http://www.hreoc.gov.au 
Suvorova, G. (2004). How to avoid the negative consequences of restructuring the network of rural schools. Russian Education and Society, 46(12), 30-41.

Wallin, D. (2008). A comparative analysis of the educational priorities and capacity of rural school districts. Educational Management Administration \& Leadership, $36(4), 566-587$.

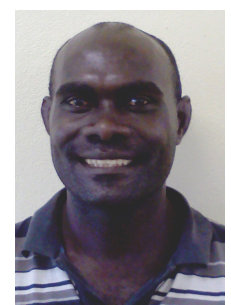

John Lenga Sisiolo is currently a Head of Department and teaching English Primary Curriculum and Educational Leadership in the School of Education, Solomon Islands College of Higher Education (SICHE). In the current course development, he is the chairperson of the Graduate Diploma in Educational Leadership and Management Course Committee. In the most recent Partnership with the University of Waikato, he contributed to the review of the language courses of the School of Education, SICHE. His interests are in educational leadership.

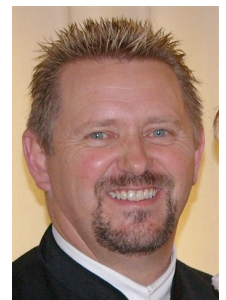

David Giles is an Associate Professor (Educational Leadership and Management) in the School of Education, Flinders University. He has extensive teaching and leadership experience in the primary, secondary and tertiary sectors. David has a particular interest in hermeneutic phenomenology and appreciative inquiry research methodologies as vehicles for exploring the experiential, relational \& phenomenological nature of educational leadership. 
